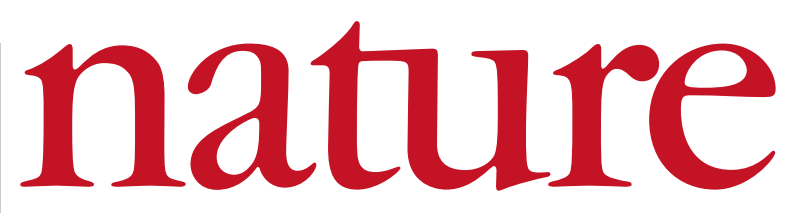

5 February 2004 Volume 427 Issue no 6974

\title{
Defeated but not deterred
}

Animal-rights protesters have helped to end plans for a primate research centre at the University of Cambridge. But despite the activists' triumphant soundbites, their victory is unlikely to be repeated elsewhere.

listis

t doesn't make pleasant reading, but the gloating should come as no surprise. When the University of Cambridge decided last week to scrap plans for a primate research centre, animal-rights protesters who campaigned against the facility were in bellicose mood. "An important message has been sent out to universities across the UK," activists' group Stop Primate Experiments at Cambridge said in an e-mail to supporters. "If the mighty Cambridge can only put up a pathetic fight, then they have no chance if we were to turn our attention to them."

For any university that conducts animal research - not just the small number that use primates - this sounds like a worrying challenge. Activists clearly helped to derail the Cambridge centre. Fears about protests prolonged the planning inquiry. The need for security at the site bumped up running costs. Concerns that building workers would be threatened led some to wonder whether it could be built. When costs jumped by $\mathfrak{E} 8$ million (US $\$ 15$ million) to $£ 32$ million, the university had to pull the plug.

But that does not mean that the protesters are guaranteed other victories. Primate research is already being done in Britain, and does not need to be moved to centralized facilities. The activists also ignore public and media opinion towards animal experiments, which is more positive than they dare acknowledge. Universities and funding bodies should not prepare for war with animal-rights activists, but continue with the lobbying that is winning people round.

There are several reasons why the Cambridge débâcle is unlikely to be repeated. Funding bodies and universities are considering different approaches after observing the planning process there. Researchers who argue against the need for centralized animal labs, such as neuroscientist Colin Blakemore, who has faced death threats for advocating animal research, may now hold sway.
Blakemore believes that embedding animal facilities in research groups makes for better science and better public relations. Animal work complements the other techniques of the life sciences, from in vitro studies to computer modelling. Separating it from mainstream science, he says, hampers research and makes animal research appear backwards-looking. As chief executive of the Medical Research Council (MRC), Blakemore, together with the Wellcome Trust, the major funder for the Cambridge centre, is exploring how Cambridge can continue to do primate work. From the MRC's point of view, this means funding the groups that already have primate facilities.

Some universities will nevertheless decide that centralized animal facilities are the best way to improve animal care. They are likely to face threats of violence, but there is every reason to think they can resist. Opinion polls suggest broad support among the public for strictly regulated animal research. And the reaction of the media towards the Cambridge decision has been overwhelmingly proscience. Grilled on Today, the BBC's flagship radio news show, one activist appeared badly out of his depth.

Good public relations could head off future protests. The Research Defence Society (RDS), for example, regularly discusses animal experiments with the public and explains why they are needed. This must be a better way forward than one option considered for the Cambridge facility - retreating to a fortified lab at a secure but secretive site such as Porton Down, owned by the Ministry of Defence.

Contrast this with the situation in the Netherlands and Switzerland, where animal researchers sometimes show members of the public round their lab during open days. No university in Britain could risk running such events. But unless we pursue a policy of openness, such events will never be possible, and the Cambridge decision will not be the campaigners' last victory.

\section{Sound thinking}

For city dwellers, maps of noise pollution are a good example of what science can do to improve quality of life.

A three-dimensional (3D) computer graphic can be worth a thousand words. The European Union's efforts to create 3D noise maps of its cities, railways and airports (see page 480) have given experts the tools both to assess the noise pollution to which its citizens are exposed, and to simulate how it can be muffled by intelligent planning of buildings, acoustic shields and speed limits. And less sophisticated versions of the maps have been made available to the public, bringing science closer to the people.

The maps are stunning, with average noise levels superimposed on $3 \mathrm{D}$ visualizations of entire cities in coloured contours ranging from pale-green - less than 45 decibels - to deep blue for greater than 79 decibels. They are a powerful way for politicians and the public to better understand noise, and to participate more meaningfully in urban-development and noise-action schemes that were previously limited to experts. Parisians, for example, can now go to the web to look up the noise levels in their street, or even on the façade of their apartment. Where anecdotal evidence and parochial complaints once reigned, the public can now both better argue its own particular gripes and be convinced at a glance of the broader benefits of unpopular controls, such as stricter traffic speed limits.

There is good reason to make a din. Some 80 million Europeans already suffer noise above 65 decibels, enough to cause lost sleep, stress, high blood pressure and even heart attacks, and a further 170 million endure levels that are simply annoying. And traffic of all kinds - the principal source of noise pollution - is set to increase.

Noise modelling is not rocket science, but more research is needed to improve the quality of the geographical information systems and noise data used and to refine the maths and physics of the models. Materials science could bring us quieter road surfaces and more effective acoustic shields, and engineering and fuel science could give us quieter engines. The effect of noise on people and their health also needs to be better understood. The European Union should be congratulated for setting about drafting such a research agenda; other countries should sit up and listen. 